\title{
THE INFLUENCE OF IONIC COMPOSITION ON THE ELECTRODISSOLUTION AND PASSIVATION OF IRON ELECTRODES IN POTASSIUM CARBONATE- BICARBONATE SOLUTIONS IN THE 8.4-10.5 pH RANGE AT $25^{\circ} \mathrm{C}$
}

\author{
E. B. Castro, ${ }^{*}$ C. R. Valentini, $\dagger$ C. A. Moina, $†$ J. R. Vilche* \\ and A. J. Arvia*
}

\begin{abstract}
* Instituto de Investigaciones Fisicoquimicas Teóricas y Aplicadas, INIFTA, Facultad de Ciencias Exactas, Universidad Nacional de La Plata, Casilla de Correo 16, Sucursal 4, 1900 La Plata, Argentina † Instituto Nacional de Tecnologia Industrial, INTI, Sector Electroquimica Aplicada, C.C. 157,1650 San Martin, Argentina
\end{abstract}

\begin{abstract}
The influence of ionic composition on the electrodissolution and passivation of iron electrodes in potassium carbonate/bicarbonate buffers is studied over the concentration range of anions compatible with the regulating capacity of the buffer, at $25^{\circ} \mathrm{C}$, by using voltammetric and rotating disc electrode techniques. Data are discussed on the basis that the interaction between $\mathrm{Fe}^{2+}$ and $\mathrm{HCO}_{3}^{-}$ions plays an important role at the outer part of the passivating layer where the local $\mathrm{pH}$ resulting from the thickening of the passivating layer is determined by the coupling of different ionic equilibria.
\end{abstract}

\section{INTRODUCTION}

THE CORROSION and passivation of iron in aqueous solutions containing carbonate and bicarbonate ions has been investigated for different purposes extending from the use of iron in absorbing carbon dioxide systems to changes in susceptibility to corrosion fatigue and stress corrosion cracking. ${ }^{1-31}$ Recently, corrosion and passivation of iron in carbonate-bicarbonate solutions at $\mathrm{pH} 8.9$ were voltammetrically studied in the $0-75^{\circ} \mathrm{C}$ range by changing the ionic strength and stirring conditions. ${ }^{31}$ The anodic layer formed under non-equilibrium conditions involves three stages, namely the prepassive layer formation, the growth of the outer part of the passive layer which behaves as a gelatinous hydrous iron hydroxide layer, and the electrodissolution of iron through the passive layer. The latter process is considerably influenced by the presence of carbonate and bicarbonate ions in solution and implies a complex reaction which is under mixed control. The different contributions to the reaction can be sorted out by combining the rotating disc and linear potential sweep voltammetric techniques.

From previous studies it was concluded that the first stages of the reaction of iron in carbonate-bicarbonate buffer are not essentially different from those already known in other slightly alkaline solutions. ${ }^{32}$ This is not, however, the case for the electrodissolution of iron through the prepassive layer.

The present paper attempts to establish the degree of participation of the carbonate and bicarbonate ions in the electrodissolution of iron through the passivating layer. For this purpose the ionic composition of the electrolyte was changed 
over the entire range of relative concentration of anions compatible with the regulating capacity of the buffer solution in the 8.4-10.5 pH range. Voltammetric and rotating disc electrode data obtained with these solutions are congruently interpreted in terms of the main interaction of $\mathrm{HCO}_{3}^{-}$ions with $\mathrm{Fe}^{2+}$ ions at the outer part of the passivating layer where the local $\mathrm{H}^{+}$ion concentration resulting from the thickening of the passivating layer becomes determined through the coupling of the different ionic equilibria.

\section{EXPERIMENTAL METHOD}

The experimental arrangement was essentially the same as that already described in previous publications. ${ }^{19.31}$ Polycrystalline iron ('Specpure', Johnson Matthey Chemicals Ltd) working electrodes in the form of rotating disc $\left(0.070 \mathrm{~cm}^{2}\right.$ apparent area) axially embedded on PTFE cylinder were employed. The iron electrode pretreatment before each voltammetric measurement consisted of initially a mechanical polishing using successively 400 and 600 grade emery papers, 1 and $0.3 \mu$ grits alumina-acetone, and fine grade diamond paste-acetone suspensions. After polishing the electrode was cleaned with acetone and repeatedly rinsed in thrice distilled water. Finally, the iron electrode was cathodically polarized for $10 \mathrm{~min}$ at potentials sufficiently negative to achieve net hydrogen evolution. These electroreduced iron surfaces gave very reproducible electrochemical results. The counter electrode was a large area platinum sheet previously cleaned by using conventional procedures. Potentials were measured against an SCE properly shielded, but in the text they are referred to the NHE scale. The electrolyte solutions consisted of $x \mathrm{M} \mathrm{KHCO}_{3}+y \mathrm{M} \mathrm{K}_{2} \mathrm{CO}_{3}(0.075 \leqslant x \leqslant 2.5 ; 0.0015 \leqslant y \leqslant 1.5)$, covering the 8.4-10.5 pH range. At each $\mathrm{pH}$ values of $x$ and $y$ were adjusted to cover a wide ionic strength range. For the sake of comparison some measurements were carried out in $0.075 \mathrm{M} \mathrm{Na}_{2} \mathrm{~B}_{4} \mathrm{O}_{7}+0.6 \mathrm{M} \mathrm{H}_{3} \mathrm{BO}_{3}+z \mathrm{M} \mathrm{KHCO}_{3}, 0 \leqslant z \leqslant 0.25$, $\mathrm{pH} 7.5$, which correspond to a $\mathrm{CO}_{3}^{2-} / \mathrm{HCO}_{3}^{-}$concentration ratio lower than $1.9 \times 10^{-3}$. Solutions were prepared from analytical grade (p.a. Merck) reagents and twice distilled water, previously boiled to remove $\mathrm{CO}_{2}$.

Voltammetric runs were performed at $25^{\circ} \mathrm{C}$ under purified nitrogen gas saturation, between preset cathodic $\left(E_{s, c}\right)$ and anodic $\left(E_{s, a}\right)$ switching potentials at potential sweep rates $(v)$ in the $0.005-0.25 \mathrm{~V} \mathrm{~s}^{-1}$ range. The rotation speed of the $R D E(\omega)$ was varied in the $0-2580 \mathrm{rpm}$ range.

Scanning electron micrographs were obtained in an SEM-Philips 505/B with specimens previously cleaned in bidistilled water and ethanol, dried and gold metallized. Some specimens were subjected to extended ultrasonic cleaning previous to SEM observations to remove anodic surface products.

\section{EXPERIMENTAL RESULTS}

The voltammogram run from $-0.98 \mathrm{~V}$ upwards at $0.025 \mathrm{~V} \mathrm{~s}^{-1}$ in still $0.75 \mathrm{M}$ $\mathrm{KHCO}_{3}+0.05 \mathrm{M} \mathrm{K}_{2} \mathrm{CO}_{3}$ solution, $\mathrm{pH} \mathrm{8.9}$, shows (Fig. 1) three anodic peaks at

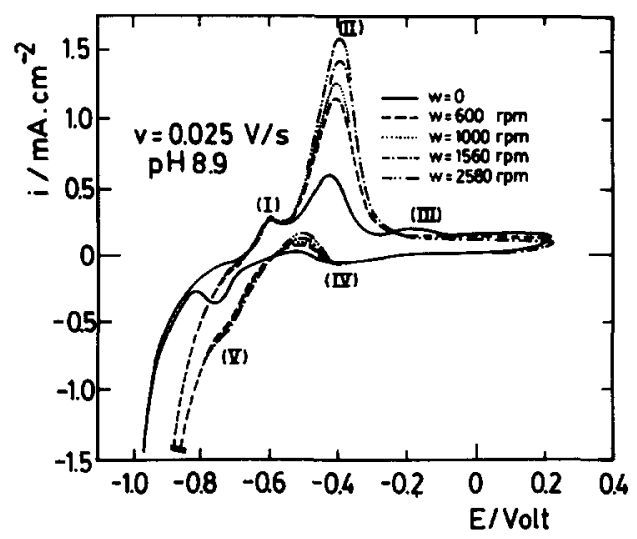

Fig. 1. Influence of $\omega$ on the voltammograms run between $-0.98 \mathrm{~V}$ and $0.23 \mathrm{~V}$ at $0.025 \mathrm{~V}$ $\mathrm{s}^{-1}$ in $0.75 \mathrm{M} \mathrm{KHCO}_{3}+0.05 \mathrm{M} \mathrm{K}_{2} \mathrm{CO}_{3}$ solution, $\mathrm{pH} 8.9$. 


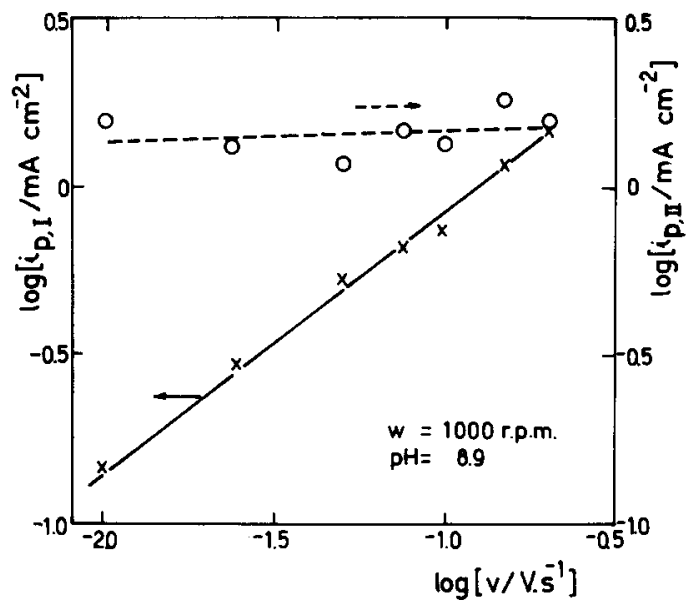

FtG. 2. Dependence of $v$ on $i_{p, \mathrm{I}}$ and $i_{p . \mathrm{II}}$ in $0.75 \mathrm{M} \mathrm{KHCO}_{3}+0.05 \mathrm{M} \mathrm{K}_{2} \mathrm{CO}_{3}, \mathrm{pH} 8.9$, at $\omega$ $=1000 \mathrm{rpm}$.

$c a-0.60 \mathrm{~V}$ (peak I), $-0.43 \mathrm{~V}$ (peak II) and $-0.18 \mathrm{~V}$ (peak III), and the reverse scan from $0.23 \mathrm{~V}$ downwards presents two cathodic peaks at $c a-0.40 \mathrm{~V}$ (peak IV) and $-0.76 \mathrm{~V}$ (peak V). The large cathodic current recorded at potentials more negative than $c a-0.80 \mathrm{~V}$ mainly corresponds to the hydrogen evolution reaction. Under stirring, the charge and height of peak II increase considerably as $\omega$ increases, peak III practically disappears, while no influence of $\omega$ on peak I is noticed. Stirring provokes an apparent slight reactivation of the electro-oxidation process at $c a-0.55 \mathrm{~V}$ during the negative going potential sweep and a large depolarization of the HER. At constant $\omega$, the height of peak I $\left(i_{p, \mathrm{I}}\right)$ fits a linear $\log i_{p, \mathrm{I}}$ vs $\log v$ relationship with the slope $0.85 \pm 0.10$, whereas the height of peak II $\left(i_{p, I I}\right)$ after passive current baseline correction becomes practically independent of $v$ in the $0.005-0.25 \mathrm{~V} \mathrm{~s}^{-1}$ range (Fig. 2).

Comparable results are obtained in the whole range of $\mathrm{pH}$ and ionic strength covered in this work (Figs 3 and 4). For constant $\mathrm{pH}, v$ and $\omega$, both anodic peaks I and II, as well as the reactivation of electro-oxidation during the negative going potential scan, increase according to the ionic strength.

To attempt to evaluate the kinetic relationships of peak I, in principle, free of the interference due to peak II, voltammetric data from still solutions were preferentially considered. At constant $v, i_{p, \mathrm{I}}$ increases according to the concentration of bicarbonate ion $\left(c_{\mathrm{HCO}_{\overline{3}}}\right)$. A linear $\log i_{p, \mathrm{I}} \mathrm{vs} \log c_{\mathrm{HCO}_{3}^{-}}$relationship results at high bicarbonate ion concentration, its slope tends to one as the $\mathrm{pH}$ decreases (Fig. 5). From this relationship one concludes that there is a predominant influence of bicarbonate ion concentration on $i_{p, \mathrm{I}}$. For a fixed bicarbonate ion concentration, the $\mathrm{pH}$ changes more than two units and accordingly $\log C_{\mathrm{CO}_{3}^{-}}$varies at least two decades. At low bicarbonate ion concentration and constant $v$, the corresponding peak potential, $E_{p . \mathrm{I}}$ changes about $-0.05 \pm 0.01 \mathrm{~V} / \mathrm{pH}$ unit, but $i_{p, \mathrm{I}}$ becomes practically independent of $\mathrm{pH}$.

In the whole range of solution composition, the value of $i_{p \text {.II }}$ corrected for the baseline current increases linearly with $\omega^{1 / 2}$ (Fig. 6), but the slopes of the straight lines and their intercepts to the origin of coordinate increase according to the concen- 


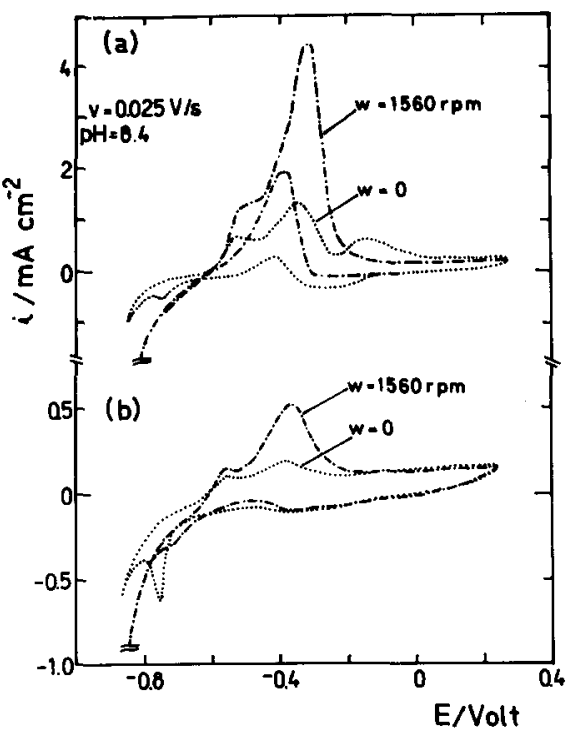

FIg. 3. Influence of the solution composition at $\mathrm{pH} 8.4$ on the voltammograms run at $0.025 \mathrm{~V} \mathrm{~s}^{-1}$ under $\omega=0$ and $\omega=1560 \mathrm{rpm}$ conditions. (a) $2.5 \mathrm{M} \mathrm{KHCO}_{3}+0.05 \mathrm{M} \mathrm{K}_{2} \mathrm{CO}_{3}$; (b) $0.25 \mathrm{M} \mathrm{KHCO}_{3}+0.005 \mathrm{M} \mathrm{K}_{2} \mathrm{CO}_{3}$.

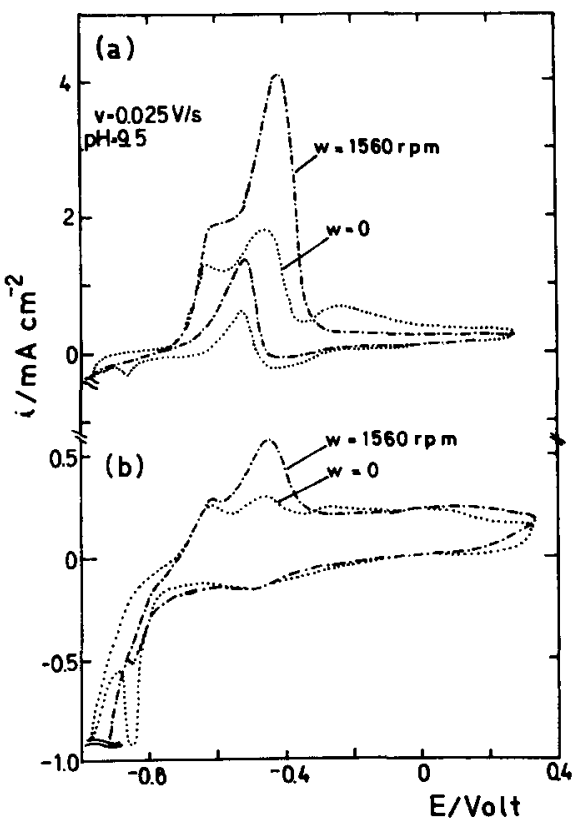

Fig. 4. Influence of the solution composition at $\mathrm{pH} 9.5$ on the voltammograms run at $0.025 \mathrm{~V} \mathrm{~s}^{-1}$ under $\omega=0$ and $\omega=1560$ rpm conditions. (a) $2.5 \mathrm{M} \mathrm{KHCO}_{3}+0.5 \mathrm{M} \mathrm{K}_{2} \mathrm{CO}_{3}$; (b) $0.25 \mathrm{M} \mathrm{KHCO}_{3}+0.05 \mathrm{M} \mathrm{K}_{2} \mathrm{CO}_{3}$. 


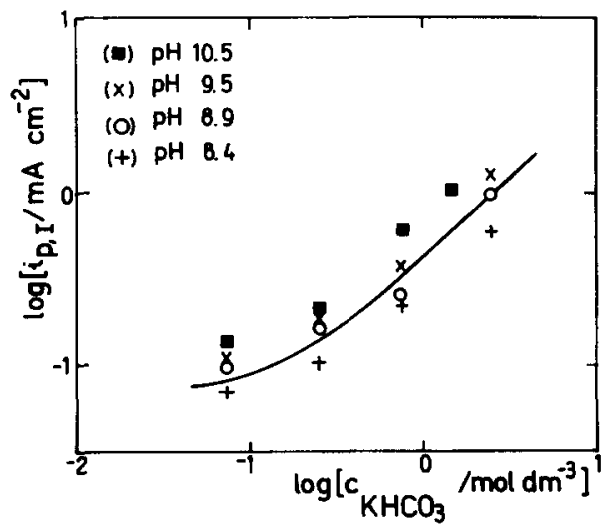

FIG. 5. Dependence of $c_{\mathrm{KHCO}_{3}}$ on $i_{p, \mathrm{I}}$ at $v=0.025 \mathrm{~V} \mathrm{~s}^{-1}$ and $\omega=0 .(+) \mathrm{pH} 8.4 ;(\bigcirc) \mathrm{pH} 8.9$; (X) $\mathrm{pH} 9.5 ;(\mathbf{0}) \mathrm{pH} 10.5$.

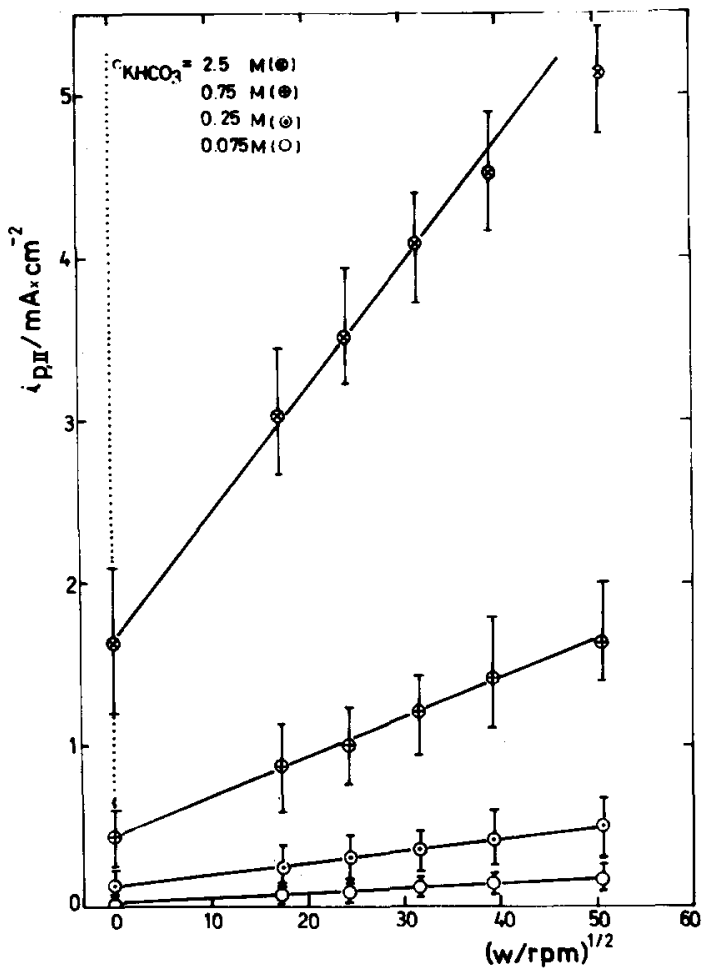

FIG. 6. Dependence of $\omega$ on $i_{p, \text { II }}$ at $0.025 \mathrm{~V} \mathrm{~s}^{-1}$ in $x \mathrm{M} \mathrm{KHCO}_{3}+y \mathrm{M} \mathrm{K}_{2} \mathrm{CO}_{3}$ solutions $(0.075 \leqslant x \leqslant 2.5 ; 0.0015 \leqslant y \leqslant 1.5)$ covering the $8.4-10.5 \mathrm{pH}$ range. 


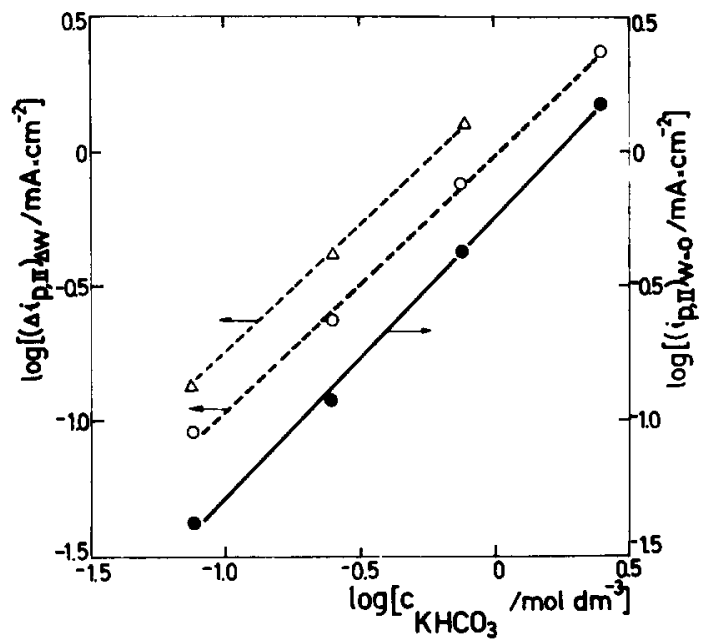

FIG. 7. Dependence of $c_{\mathrm{KHCO}_{3}}$ on $i_{p, \mathrm{II}}$ at $\omega=0(O)$ and on $\left[\left(i_{p, \mathrm{II}}\right)_{\omega}-\left(i_{p, \mathrm{II}}\right)_{\omega=0}\right]$ at both $\omega=2580 \mathrm{rpm}(\Delta)$ and $\omega=1000 \mathrm{rpm}(\mathrm{O})$, from voltammograms run at $0.025 \mathrm{~V} \mathrm{~s}^{-1}$.

tration of bicarbonate ion. The scattering of the $i_{p, \text { II }}$ vs $\omega^{1 / 2}$ plots at constant bicarbonate ion concentration, takes into account the overall results covering wide $\mathrm{pH}$ and carbonate ion concentration ranges. Results obtained in borate-boric acid buffer at $\mathrm{pH} 7.5$ containing different concentrations of bicarbonate ion after correction for the borate-boric acid blank, yield the same $i_{p, \mathrm{II}}$ vs $\omega^{1 / 2}$ plots as those shown in Fig. 6. From the voltammetric data in still and stirred solutions, the following relationships are derived (Fig. 7):

$$
\begin{aligned}
& \left(\frac{\partial \log \left(i_{p, \mathrm{II}}\right)_{\omega=0}}{\partial \log c_{\mathrm{HCO}_{\overline{3}}}}\right)_{\omega=0}=1.05 \pm 0.10 \\
& \left(\frac{\partial \log \left[\left(i_{p, \mathrm{II}}\right)_{\omega}-\left(i_{p, \mathrm{II}}\right)_{\omega=0}\right]}{\partial \log c_{\mathrm{HCO}_{\overline{3}}}}\right)_{\omega}=0.95 \pm 0.15 .
\end{aligned}
$$

These results indicate that peak II is mainly related to a process under bicarbonate ion transport control. At a constant $\omega$, the dependence of $i_{p, \mathrm{II}}$ on bulk $\mathrm{pH}$ (Fig. 8) yields the following kinetic data:

$$
\begin{aligned}
& \left(\frac{\partial \log i_{p, \mathrm{II}}}{\partial \mathrm{pH}}\right)_{c_{\mathrm{CO}_{3}^{2-}}}=-1.0 \pm 0.1 \\
& \left(\frac{\partial \log i_{p, \mathrm{II}}}{\partial \mathrm{pH}}\right)_{c_{\mathrm{HCO}_{3}^{-}}}=0 \pm 0.1
\end{aligned}
$$

which confirm that besides $\omega$, the bicarbonate ion concentration determines the charge involved in peak II. Similar conclusions come from the influence of both $\omega$ and bicarbonate ion concentration on the reactivation of the electro-oxidation process detected during the negative going potential excursions (Figs 1, 3 and 4).

The systematic change of either $E_{s, a}$ (Fig. 9a) or $E_{s, c}$ (Fig. 9b) in the voltammetric measurements furnishes evidence of the conjugated nature of peaks I and V. Peak I can be attributed to the formation of the first layers of the prepassive surface film, 


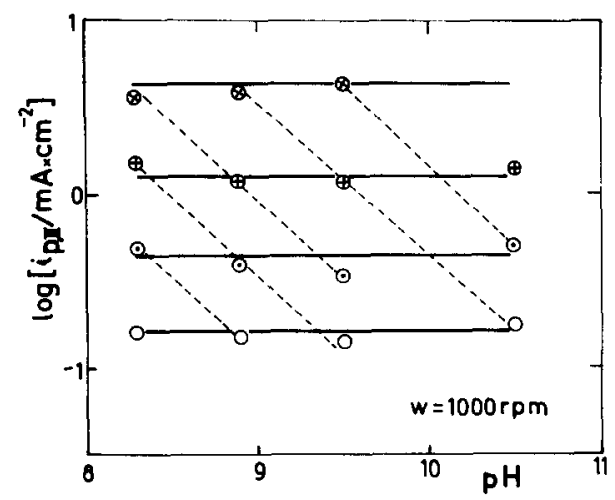

FIG. 8. Dependence of $\mathrm{pH}$ on $i_{p, \mathrm{II}}$ for different carbonate-bicarbonate solution compositions from voltammograms run at $0.025 \mathrm{~V} \mathrm{~s}^{-1}$ and $\omega=1000 \mathrm{rpm}$. (®) $2.5 \mathrm{M} \mathrm{KHCO}_{3}$; $(\oplus) 0.75 \mathrm{M} \mathrm{KHCO}_{3}$; $(\odot) 0.25 \mathrm{M} \mathrm{KHCO}_{3}$; (О) $0.075 \mathrm{M} \mathrm{KHCO}_{3}$. Full lines correspond to solution compositions at constant $\mathrm{KHCO}_{3}$ concentration, while dotted lines indicate solution compositions at constant $\mathrm{K}_{2} \mathrm{CO}_{3}$ concentration.

probably the monolayer of $\mathrm{Fe}(\mathrm{OH})_{2}$ species as earlier suggested for iron in strongly alkaline media, ${ }^{33-36}$ in slight acid solutions containing sulphate ion, ${ }^{37}$ and also more recently in boric acid-borate buffers. ${ }^{32,38}$ In the early stages of iron electro-oxidation the active dissolution to soluble $\mathrm{Fe}$ (II) competes with the $\mathrm{Fe}(\mathrm{OH})_{2}$ electroformation. The heights of peaks I and $\mathrm{V}$ are independent of $E_{s, a}$, and accordingly, these peaks can be, in principle, assigned to the electroformation and electroreduction of the inner surface layer. On the other hand, processes taking place in the potential range of peak II are associated with the growth of the surface film, whose composition and structure depend on both potential and $\mathrm{pH}$. The chemical dissolution of the passive film is mainly controlled by the bicarbonate ion concentration in solution and,

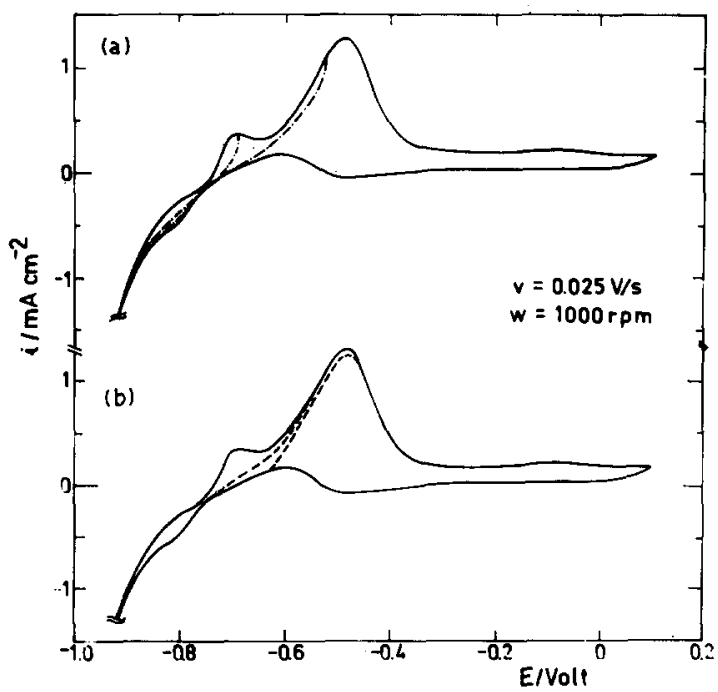

FIG. 9. Influence of $E_{s, a}$ (a) and $E_{s, c}$ (b) on the voltammograms run at $0.025 \mathrm{~V} \mathrm{~s}^{-1}$ and $\omega=$ $1000 \mathrm{rpm}$ in $0.75 \mathrm{M} \mathrm{KHCO}_{3}+0.05 \mathrm{M} \mathrm{K}_{2} \mathrm{CO}_{3}$ solution $\mathrm{pH} 8.9$. 
therefore, by the hydrodynamic conditions prevailing in the system. SEM observations (Fig. 10) performed on specimens previously held during $120 \mathrm{~min}$ at a constant potential in the potential range of peak II under stirring show a remarkable faceting after removal of the surface products. The passive state is reached at potentials exceeding the potential range of peak III where the formation of $\mathrm{Fe}$ (III) species are thermodynamically possible. $9,39-42$

\section{DISCUSSION}

The voltammograms obtained in a wide range of $v, \omega$ and ionic strength show that the active to passive transition of iron in slightly alkaline aqueous solutions containing carbonate and bicarbonate ions strongly depends on hydrodynamics and the electrolyte composition. The dissolution and passivation of the metal involve two stages associated with the anodic peaks I and II. Peak I is practically independent of $\omega$, whereas the influence of $\omega$ on the height of peak II implies a combined iron electro-oxidation reaction under mass transfer control. The kinetic analysis of these two stages was considered in detail in a previous publication. ${ }^{31}$ The formation of the passivating layer in the presence of the carbonate/bicarbonate system yields a carbon-containing passive layer, whether this incorporation is due to $\mathrm{CO}_{3}^{2-}$ or $\mathrm{HCO}_{3}^{-}$ was a matter open to discussion.

The voltammetric response of iron in carbonate-bicarbonate solutions at low bicarbonate ion concentration reveals that both the charge and height of peak I are practically independent of $\omega, \mathrm{pH}$ and ionic strength, but increase linearly with $v$. These results are in close agreement with those recently reported for iron in boric acid-borate solutions in the $7.5-9.2 \mathrm{pH}$ range. ${ }^{32}$ Therefore, the first oxidation level of iron can be associated with the surface formation of $\mathrm{Fe}(\mathrm{OH})_{2}$ species according to the overall reaction:

$$
\mathrm{Fe}+2 \mathrm{H}_{2} \mathrm{O} \rightleftharpoons \mathrm{Fe}(\mathrm{OH})_{2}+2 \mathrm{H}^{+}+2 e^{-} \text {. }
$$

The complex nature of reaction (3) in slight acid, neutral and base electrolytes was discussed in previous publications. ${ }^{32-38}$ At high bicarbonate ion concentration both the charge and height of peak I increase with the bicarbonate ion concentration although they are practically independent of $\omega$ (Fig. 5). This effect can be explained by the partial removing of the prepassive $\mathrm{Fe}(\mathrm{OH})_{2}$ layer according to its chemical dissolution assisted by bicarbonate ion:

$$
\mathrm{Fe}(\mathrm{OH})_{2}+\mathrm{HCO}_{3}^{-} \rightarrow \mathrm{CO}_{3}^{2-}+\mathrm{OH}^{-}+\mathrm{Fe}^{2+}+\mathrm{H}_{2} \mathrm{O} \text {. }
$$

The second anodic stage associated with peak II can be related to the growth of the anodic layer with the simultaneous electrodissolution of iron through the hydrous prepassive layer and the chemical dissolution of the outer part of the porous oxide layer according to reaction (4). The contribution of electrodissolution becomes more clearly distinguishable as $\omega$ increases both in the potential range of peak II and also during the electro-oxidation process in the reverse cathodic scan. The presence of carbonate and bicarbonate ions also operates by precipitating ferrous ions resulting from the electrodissolution of the base metal and by contributing to the transport of ions through the complex passive layer consisting of an inner thin oxide layer and an outer hydrous iron oxide layer of a gelatinous structure. ${ }^{43}$ Then, at the outer layer, dissolved ferrous ions can be precipitated either as $\mathrm{FeCO}_{3}$ or $\mathrm{Fe}\left(\mathrm{HCO}_{3}\right)_{2}$, according to the following overall coupled reactions: 

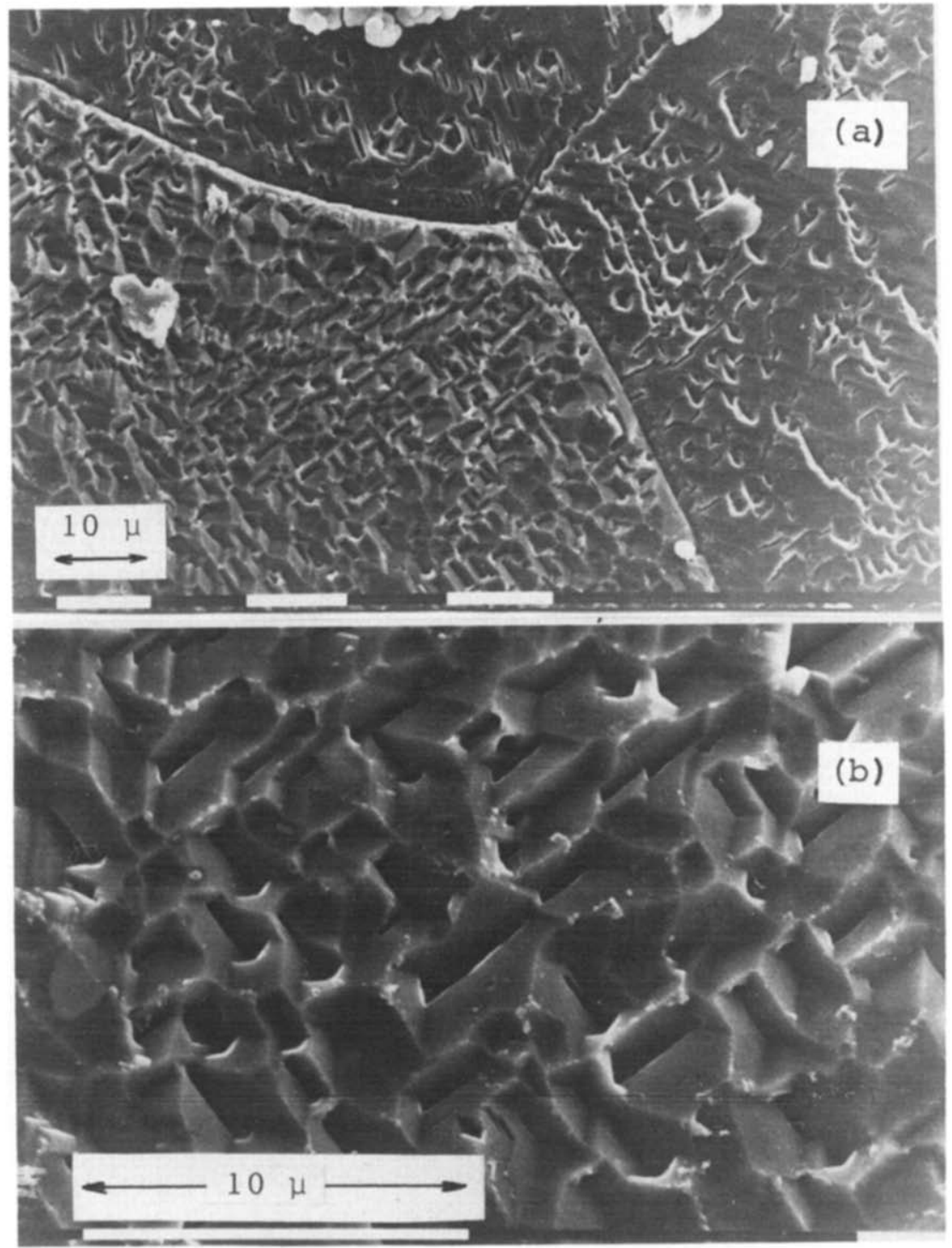

Fig. 10. Scanning electron micrograph of an iron specimen after holding the potential at $E_{p \text {.II }}$ during $120 \mathrm{~min}$ in $2.5 \mathrm{M} \mathrm{KHCO}_{3}+0.16 \mathrm{M} \mathrm{K}_{2} \mathrm{CO}_{3}$ solution and removing the surface products by ultrasonic treatment. 


$$
\begin{gathered}
\left(\mathrm{CO}_{3}^{2-}\right)+\left(\mathrm{Fe}^{2+}\right) \rightleftharpoons\left(\mathrm{FeCO}_{3}\right) \\
+\left(\mathrm{H}^{+}\right) \backslash \uparrow-\left(\mathrm{H}^{+}\right) \\
\left(\mathrm{HCO}_{3}^{-}\right)+\left(\mathrm{Fe}^{2+}\right) \rightarrow\left(\mathrm{FeHCO}_{3}^{+}\right) \\
\left(\mathrm{FeHCO}_{3}^{+}\right)+\left(\mathrm{HCO}_{3}^{-}\right) \rightleftharpoons \mathrm{Fe}\left(\mathrm{HCO}_{3}\right)_{2}
\end{gathered}
$$

where the parentheses denote species in the outer part of the passivating layer. The incorporation of anions into the passive layer is favoured by the fact that the applied potential is quite likely more positive than both the potential of zero charge of the metal and the isoelectric point of the colloidal part of the passive layer. Previous studies were insufficient to decide whether the main contribution to the formation of the iron salt was due to either carbonate or bicarbonate ion. A tentative explanation was given in terms of reaction (5) but reaction (6) should also be considered as a likely process. Reactions (5) and (6) coupled to reaction (4) imply the corrosion of the metal, as evaluated through the current resulting in the potential range of peak II. The change in the inhibitive properties of the entire surface layer results as a competition between the passive layer formation and its chemical dissolution. In any case, besides reactions (5) and (6) in the $\mathrm{pH}$ range of the present study the formation of ferrous ion implies also the participation of the following equilibria:

$$
\begin{aligned}
\mathrm{Fe}^{2+}+\mathrm{OH}^{-} & \rightleftharpoons \mathrm{FeOH}^{+} \\
\mathrm{FeOH}^{+}+\mathrm{OH}^{-} & \rightleftharpoons \mathrm{Fe}(\mathrm{OH})_{2}
\end{aligned}
$$

which contribute to the thickening of the anodic layer.

The present results were obtained over a large range of $\mathrm{HCO}_{3}^{-} / \mathrm{CO}_{3}^{2-}$ concentration ratio at practically constant $\mathrm{pH}$ values, as the greatest difference between experimental and calculated $\mathrm{pH}$ reaches $0.15 \mathrm{pH}$ units. This means that the kinetic effects discussed before must be principally related to the influence of bicarbonate and carbonate ions in solution. Therefore, at a constant $\mathrm{pH}$, the rate equation derived from reactions (5) and (6) can be written in terms of current density as follows:

$$
\begin{aligned}
& i_{\mathrm{II}}=2 F k_{5} c_{\mathrm{CO}_{3}^{2}-} c_{\mathrm{Fe}^{2+}}=K_{5} c_{\mathrm{CO}_{3}^{2-}} \\
& i_{\mathrm{II}}=2 F k_{6} c_{\mathrm{HCO}_{3}^{2-}} c_{\mathrm{Fe}^{2+}}=K_{6} c_{\mathrm{HCO}_{3}^{-}}
\end{aligned}
$$

where $K_{i}$ is the potential-dependent electrochemical rate constant of either reaction (9) or (10) already discussed in a previous publication. ${ }^{31}$ In both cases, however, the concentration of ferrous ion at the interface is determined by the solubility product of the iron salts. Hence, equations (9) and (10) can be expressed as first order rate constants in terms of carbonate and acid carbonate ion, respectively. Thus, taking into account results shown in Fig. 8 and the carbonate-bicarbonate ion equilibrium reaction one obtains:

$$
\begin{aligned}
& \left(\frac{\partial \log i_{p, \mathrm{II}}}{\partial \log c_{\mathrm{HCO}_{3}^{-}}}\right)_{c_{\mathrm{CO}_{3}^{2-}}}=\left(\frac{\partial \log i_{p, \mathrm{II}}}{\partial \log c_{\mathrm{H}^{+}}}\right)_{c_{\mathrm{CO}_{3}^{2-}}} \times\left(\frac{\partial \log c_{\mathrm{H}^{+}}}{\partial \log c_{\mathrm{HCO}_{\overline{3}}^{-}}}\right)_{c_{\mathrm{CO}_{3}^{2-}}}=(1) \times(1)=1 \\
& \left(\frac{\partial \log i_{p, \mathrm{II}}}{\partial \log c_{\mathrm{CO}_{3}^{2-}}}\right)_{c_{\mathrm{HCO}_{\overline{3}}^{-}}}=\left(\frac{\partial \log i_{p, \mathrm{II}}}{\partial \log c_{\mathrm{H}^{+}}}\right)_{c_{\mathrm{HCO}_{\overline{3}}^{-}}} \times\left(\frac{\partial \log c_{\mathrm{H}^{+}}}{\partial \log c_{\mathrm{CO}_{3}^{2-}}}\right)_{c_{\mathrm{HCO}_{\overline{3}}^{-}}}=(0) \times(-1)=0 .
\end{aligned}
$$


The present results indicate that at constant $v$ and $\omega$ values $\left(\partial \log i_{p, \mathrm{II}} / \partial \log \right.$ $\left.c_{\mathrm{HCO}_{3}^{-}}\right)_{c_{\mathrm{CO}^{2-}}}=1$ and that $\left(\partial \log i_{p, \mathrm{II}} / \partial \log c_{\mathrm{CO}_{3}^{2-}}\right)_{c_{\mathrm{HCO}_{3}^{-}}}=0$. These reaction pseudo-orders indicate that reactions (4) and (6) become definitely kinetically relevant as compared to reaction (5). The first order and the zero order are obviously consistent with the reaction order of $i_{p, \mathrm{II}}$ with respect to $\mathrm{H}^{+}$ion, evaluated at constant $\mathrm{CO}_{3}^{2-}$ and $\mathrm{HCO}_{3}^{-}$ ion concentration from equations (2a) and (2b), respectively (Fig. 8).

In a previous work ${ }^{31}$ it was established that a constant $\mathrm{pH}$

$$
\left(\frac{\partial \log i_{p, \mathrm{II}}}{\partial \log c_{\mathrm{HCO}_{3}^{-}}}\right)_{c_{\mathrm{H}^{+}}}=\left(\frac{\partial \log i_{p, \mathrm{II}}}{\partial \log c_{\mathrm{CO}_{3}^{2}}}\right)_{c_{\mathrm{H}^{+}}}=1
$$

and from these relationships it was not possible to decide the particular influence of bicarbonate or carbonate ions in the electrodissolution and passivation of iron in carbonate/bicarbonate buffers.

Therefore, one concludes that in the carbonate/bicarbonate buffer solutions the kinetic response of iron in the potential range of the prepassive stage is principally determined by the concentration of bicarbonate ions. This result is consistent with the fact that the thickening of the passive layer through reactions such as (7) and (8) implies a local acidification which moves the bicarbonate-carbonate ion equilibrium from carbonate ion to bicarbonate ion.

Acknowledgements-This research project is supported by the Universidad Nacional de La Plata, the Consejo Nacional de Investigaciones Cientificas y Téchnicas and the Comisión de Investigaciones Cientificas de la Provincia de Buenos Aires. This work was developed in the frame of the INIFTA-INTI Cooperation Program for the Study of Corrosion and Passivation of Metals.

\section{REFERENCES}

1. P. Hancock and J. R. O. Mayne, J. appl. Chem. 9, 345 (1959).

2. F. Clerbois and J. Massart, Corros. Sci. 2, 1 (1962).

3. D. Gilroy and J. E. O. Mayne, Br. Corros. J. 1, 161 (1966).

4. J. G. N. Thomas and T. J. Nurse, Br. Corros. J. 2, 13 (1967).

5. J. A. von Fraunhofer, Corros. Sci. 10, 245 (1970).

6. J. G. N. Thomas, T. J. Nurse and R. Walker, Br. Corros. J. 5, 87 (1970).

7. J. M. Sutcliffe, R. R. Fessler, W. K. Boyd and R. N. Parkins, Corrosion 28, 313 (1972).

8. R. D. Armstrong and A. C. CoAtes, J. electroanal. Chem. 50, 303 (1974).

9. F. Pardieus, A. van Haute and M. Brabers, Proc. 6th Inter. Congr. Met. Corros., Sidney, pp. 269-277 (1975).

10. D. Hixson and H. H. Uhlig, Corrosion 32, 56 (1976).

11. R. D. Armstrong and A. C. Coates, Corros. Sci. 16, 423 (1977).

12. I. A. Ammar and S. A. Darwish, Metalloberfläche 31, 124 (1977).

13. J. G. N. Thomas and J. D. Davies, Br. Corros. J. 12, 108 (1977).

14. K. J. KessLer and E. Wendler-Kalsch, Werkst. Korros. 28, 78 (1977).

15. J. JelineK and P. Neufeld, Corros. Sci. 20, 489 (1980).

16. D. H. Davies and G. T. Burstein, Corrosion 36, 416 (1980).

17. E. Wendler-Kalch, Werkst. Korros. 31, 534 (1980).

18. B. G. ACKland and B. W. Cherry, Corros. Australas. 6, 8 (1981).

19. C. R. Valentini, C. A. Moina, J. R. Vilche and A. J. Arvia, Anal. Asoc. Quim. Arg. 71, 555 (1983).

20. W. SchWenK, Werkst. Korros. 34, 287 (1983).

21. A. M. Riley and J. M. Sykes, in Passivity of Metals and Semiconductors (M. Froment, ed.), pp. 661-666. Elsevier, Amsterdam (1983).

22. A. Wieckowski, E. Ghali, M. Szklarczyk and J. Sobkowski, Electrochim. Acta 28, 1619 (1983).

23. J. Avila Mendoza and J. M. Sykes, Corros. Sci. 23, 547 (1983).

24. W. Höpfner and W. J. Plieth, Werkst. Korros. 35, 366 (1984).

25. R. H. Ricci, L. B. Berardo, L. M. Gassa and J. R. Vilche, Proc. 9th Intern. Congr. Met. Corros., Vol. 3, pp. 161-168. Toronto (1984). 
26. R. N. Parkins, C. S. O'Dell and R. R. Fessler, Corros. Sci. 24, 343 (1984).

27. T. Hurlen, S. Gunvaldsen, R. Tunold, F. Blaker and P. G. Lunde, J. electroanal. Chem. 180, 511 (1984).

28. E. Wendler-Kalsch, in Fundamental Aspects of Corrosion Protection by Surface Modification (E. MacCafferty, C. R. Clayton and J. Oudar, eds), pp. 158-172. The Electrochemical Society, Pennington (1984).

29. R. N. Parkins, I. H. Craig and J. Congleton, Corros. Sci. 24, 709 (1984).

30. J. W. Lee, K. Osseo-Asare and H. W. Pickering, J. electrochem. Soc. 132, 550 (1985).

31. C. R. Valentini, C. A. Moina, J. R. Vilche and A. J. Arvia, Corros. Sci. 25, 985 (1985).

32. M. E. VeLA, J. R. VILCHE and A. J. ARviA, J. appl. Electrochem., in press.

33. J. R. Vilche and A. J. Arvia, Proc. 7th Intern. Congr. Met. Corros., Rio de Janeiro, pp. 245-267 (1978).

34. R. S. Schrebler Guzmán, J. R. Vilche and A. J. Arvia, Electrochim. Acta 24, 395 (1979).

35. J. R. VILCHE and A. J. ArviA, Acta Cient. Venez. 31, 408 (1980).

36. R. S. Schrebler Guzmán, J. R. Vilche and A. J. ArVia, J. appl. Electrochem. 11, 551 (1981).

37. J. O. Zerbino, J. R. Vilche and A. J. ArviA, J. appl. Electrochem. 11, 703 (1981).

38. M. E. Vela, J. R. Vilche and A. J. Arvia, in Passivity of Metals and Semiconductors (M. Froment, ed.), pp. 59-66. Elsevier, Amsterdam (1983).

39. M. Pourbaix, in Atlas of Electrochemical Equilibria in Aqueous Solutions. Pergamon Press, London (1966).

40. P. C. Singer and W. Stumm, J. AWWA 62, 198 (1970).

41. M. Pourbaix and X. Z. YANG, in Diagrams of Chemical and Electrochemical Equilibria. The Iron-Oxygen-Hydrogen-Water System. Rapports Techniques CEBELCOR, 138, RT. 256 (1980).

42. M. PourbaiX and A. Pourbaix (eds) in Diagrams of Chemical and Electrochemical Equilibria. Their Setting-up and Applications. Rapports Techniques CEBELCOR, 142, TR. 263 (1982).

43. O. A. Albani, J. O. Zerbino, J. R. Vilche and A. J. Arvia, Electrochim. Acta in press. 